\title{
Antitussive effect of a magnesium infusion during anesthetic emergence in patients with double-lumen endotracheal tube: a randomized controlled trial
}

\author{
Min Hur ^^, Jong Yeop Kim, Dae Hee Kimㄹ, Ji Young Yoo ${ }^{1}$, Han-Bit Shin², Bumhee Park², \\ Myungseob Kim ${ }^{1}$, Eunjeong Park ${ }^{1}$, Sung Yong Park ${ }^{1 \wedge}$ \\ ${ }^{1}$ Department of Anesthesiology and Pain Medicine, Ajou University School of Medicine, Suwon, Korea; ${ }^{2}$ Office of Biostatistics, Medical Research \\ Collaboration Center, Ajou Research Institute for Innovative Medicine, Ajou University School of Medicine, Suwon, Korea \\ Contributions: (I) Conception and design: SY Park, JY Kim, JY Yoo, DH Kim; (II) Administrative support: SY Park; (III) Provision of study materials \\ or patients: All authors; (IV) Collection and assembly of data: SY Park, M Hur, M Kim, E Park; (V) Data analysis and interpretation: HB Shin, B \\ Park, SY Park, M Hur; (VI) Manuscript writing: All authors; (VII) Final approval of manuscript: All authors. \\ Correspondence to: Sung Yong Park, MD. Department of Anesthesiology and Pain Medicine, Ajou University School of Medicine, Suwon, Korea. \\ Email: anepark@hanmail.net.
}

Background: A double-lumen endotracheal tube (DLT) inserted into the bronchus can stimulate the respiratory tracts, causing coughing. Opioids have been introduced to prevent emergence cough. However, the administration of a significant opioid dose at the end of surgery may result in undesirable events. Magnesium, common intracellular ion, suppress bronchial smooth muscle contraction and have antitussive effect. We investigated the antitussive effects of a magnesium infusion during anesthetic emergence in patients who underwent thoracic surgery requiring one-lung ventilation (OLV) anesthesia with a DLT.

Methods: One-hundred forty patients undergoing OLV anesthesia with a DLT were enrolled in this prospective, randomized double-blinded trial. In combination with a low dose of remifentanil, patients were randomly allocated to receive either magnesium sulphate (infusion of $15 \mathrm{mg} / \mathrm{kg} / \mathrm{hour}$ after a single bolus of $30 \mathrm{mg} / \mathrm{kg}$ ) or normal saline during the operation and emergence. Primary outcomes were the severity and incidence of cough during emergence.

Results: The severity of cough was assessed by the cough severity grading score: 0 , no cough; 1 , single cough; 2 , cough persistence $<5$ seconds; 3 , cough persistence $\geq 5$ seconds. There was a significant difference in the severity score of cough between the groups [median (IQR): 2 ( 0 to 3$)$ in control group vs. 0 (0 to 1$)$ in magnesium group, $\mathrm{P}=0.003]$. However, there was no significant difference in the overall incidence of cough between both groups [42 (64.6\%) in control group vs. 31 (47.7\%) in magnesium group, $\mathrm{P}=0.077$ ].

Conclusions: Magnesium attenuated the severity of cough during emergence after OLV anesthesia using a DLT without adverse events.

Keywords: Complications; cough; magnesium; one lung ventilation; thoracic surgery

Submitted May 19, 2020. Accepted for publication Aug 28, 2020.

doi: $10.21037 /$ jtd-20-1977

View this article at: http://dx.doi.org/10.21037/jtd-20-1977

^ ORCID of Min Hur: 0000-0001-5229-9444; ORCID of Sung Yong Park: 0000-0003-2395-1645. 


\section{Introduction}

Insertion of a double-lumen endotracheal tube (DLT) is considered the standard technique to achieve one-lung ventilation (OLV) (1). However, the DLT has the greater contact area of the respiratory tract, compared with single lumen tube (SLT), can increase the risk for cough reflex during emergence (2-5).

Because coughing during emergence from anesthesia can be associated with adverse events such as laryngospasm, desaturation, and pulmonary edema (6), various methods have been introduced to prevent emergence cough (6-10). Among them, there is sufficient evidence that remifentanil has a beneficial role in suppressing coughing during emergence $(6,9,10)$. Our research team has reported on the effect-site concentrations (Ce) of remifentanil that are ideal for cough suppression during emergence after general anesthesia using DLT: $1.67 \mathrm{ng} / \mathrm{mL}$ for $50 \%$ of patients and $2.28 \mathrm{ng} / \mathrm{mL}$ for $95 \%$ (10). However, the administration of a significant opioid dose at the end of surgery may result in adverse events, such as depression of ventilation, delayed awakening, and postoperative nausea and vomiting (6). As such, some limitations must be placed on increases to opioid doses administered during emergence.

Magnesium, the common intracellular ion in human being, has a fundamental role in enzymatic reactions, neurotransmission, and cell signaling $(11,12)$. It also inhibits bronchial smooth muscle contractions (11,13-15) and has been considered an alternative asthma treatment for this reason $(11,16)$. Recently published randomized controlled trials have reported an antitussive effect of magnesium on opioid-induced cough $(17,18)$. However, there have been no studies on the role of magnesium in preventing emergence cough.

Searching for possibilities to prevent emergence cough with minimal adverse effects, we hypothesized that an infusion of magnesium, in combination with a low dose of remifentanil, would be more effective in suppressing emergence cough than remifentanil alone. As such, in this prospective, randomized, double-blinded study, we investigated the antitussive effects of magnesium during recovery from anesthesia in patients who underwent OLV anesthesia with a DLT.

We present the following article in accordance with the CONSORT reporting checklist (available at http://dx.doi. org/10.21037/jtd-20-1977).

\section{Methods}

The trial was conducted in accordance with the Declaration of Helsinki (as revised in 2013) and the Harmonized Tripartite Guideline for Good Clinical Practice from the International Conference on Harmonization. The study was approved by the Institutional Review Board (Ref: AJIRBMED-OBS-17-184, registration date: July 25, 2017). After written informed consent was obtained from participants, we enrolled 140 patients, aged 19-70 years, of American Society of Anesthesiologists physical status class I-II, who were undergoing surgery requiring OLV. The exclusion criteria were a history of asthma, chronic obstructive disease, signs of upper respiratory infection, a difficult airway, and chronic taking angiotensin-converting enzyme inhibitor. This trial was registered in a public trial registry (Clinical Research Information Service, CRIS) under the identification number KCT0002445 (registration date: September 1, 2017). This study was conducted in a tertiarycare hospital (Ajou University Hospital, South Korea) from September 4, 2017 to November 14, 2019.

Before anesthesia induction, participants were randomly assigned to the control (Group C) or the magnesium group (Group M), using a computerized randomization program. The group assignments were sealed in opaque envelopes, and the only investigator responsible for preparing the study drugs was allowed to open the envelopes to do so. The investigator did not participate in the patients' anesthetic management.

Anesthesia was induced using intravenous propofol $2.0 \mathrm{mg} / \mathrm{kg}$ and effect-site targeted controlled infusion (TCI) of $1.5 \mathrm{ng} / \mathrm{mL}$ remifentanil. Remifentanil infusion began at the time of anesthetic induction. After the patient did not response to verbal command, rocuronium $1.0 \mathrm{mg} / \mathrm{kg}$ was given and manual ventilation with $100 \%$ oxygen was done for 90 seconds (s). Tracheal intubation was performed in all patients with a 35-Fr. DLT for women and 37-Fr. DLT for men. The correct positioning of DLT was confirmed with fiberoptic bronchoscopy. If repositioning was necessary, the DLT was guided into position via bronchoscope. Cuff pressure was set to 20 to $25 \mathrm{mmH}_{2} \mathrm{O}$ with a hand pressure gauge.

Five minutes after induction of anesthesia, either normal saline or magnesium sulphate was administered according to the group allocation. Patients in Group M received $30 \mathrm{mg} / \mathrm{kg}$ intravenous magnesium sulphate for $10 \mathrm{~min}$ and then $15 \mathrm{mg} / \mathrm{kg} / \mathrm{hour}$ continuously during the operation and 
anesthetic emergence (12). Patients in Group C received the same volume of normal saline over the same period.

To monitor depth of anesthesia, an $\mathrm{ADMS}^{\circledR}$ monitoring device (Unimedics CO, Korea) was attached to the front of the patient's head. This monitor provides a Unicon index of the quantitative electroencephalogram using mono-spectral power analysis, identical to the qCON index, which has been reported to maintain acceptable correlation with the BIS $(19,20)$. Anesthesia was maintained using sevoflurane and TCI of $1.5 \mathrm{ng} / \mathrm{mL}$ remifentanil to maintain blood pressure and heart rate within $20 \%$ of baseline value, and to maintain a Unicon index of 40 to 60 during surgery. In addition, $0.3 \mathrm{mg} / \mathrm{kg} /$ hour rocuronium was continuously administered intravenously to maintain muscular blockade.

Intravenous $400 \mathrm{mg}$ of ibuprofen was administered for pain control, at the beginning of wound closure. After the operation, sevoflurane was discontinued and $4 \mathrm{mg} / \mathrm{kg}$ sugammadex was given to reverse neuromuscular (NM) block, while effect-site TCI of $1.5 \mathrm{ng} / \mathrm{mL}$ remifentanil was maintained during emergence. When patients were fully awake and opened their eyes in response to a verbal command, the DLT was removed. The patients, who had not regained consciousness by $20 \mathrm{~min}$ after sevoflurane had been stopped, were withdrawn from the interventions (remifentanil and study drugs were stopped) and excluded from analysis.

The primary outcomes were the severity and incidence of cough during emergence. Cough, defined as the abdominal muscle contraction, was assessed during anesthetic emergence, which was from immediately after the discontinuation of inhalation anesthetics to $2 \mathrm{~min}$ after extubation. The severity of cough was assessed by the cough severity grading score (6): 0 , no cough; 1 , single cough; 2 , cough persistence $<5 \mathrm{~s} ; 3$, cough persistence $\geq 5 \mathrm{~s}$. Secondary outcomes were recovery profiles and hemodynamic changes during emergence.

Blood samples were obtained before administration of the study drug and at the end of surgery to measure ionized magnesium level. The times from the discontinuation of inhalation anesthetics to eye opening and to extubation, the end-tidal sevoflurane (ETSevo) concentration at eye opening, and body temperature at the end of surgery were also recorded. Mean arterial pressure, heart rate, and Unicon index were recorded after the completion of the surgery, immediately before and after extubation, and $2 \mathrm{~min}$ after extubation. The degree of sedation ( 0 : no response to stimulus, 1: response to loud verbal stimulus or physical contact, 2: responseto general voice, 3: clear consciousness) and pain score were assessed $30 \mathrm{~min}$ after post anesthesia care unit admission. Respiratory complications [bradypnea ( $<8$ breaths/min)] or a hypoxemia $\left(\mathrm{SpO}_{2}<95 \%\right.$ with $\mathrm{O}_{2}$ supplement) were assessed during the emergence period.

All data were assessed and recorded by an anesthesiologist, who was blind to the group assignments.

\section{Statistical analysis}

The sample size calculation was based on a previous study, reporting that the Ce of remifentanil for $50 \%$ of patients to prevent cough during emergence after thoracic procedure requiring DLT was $1.67 \mathrm{ng} / \mathrm{mL}$ (10). Assuming that an additional infusion of magnesium at about $1.5 \mathrm{ng} / \mathrm{mL}$ of remifentanil would reduce the incidence of emergence cough by more than half, 65 patients were required in each group for a type 1 error of 0.05 and a power of 0.8 . A total of 140 patients were recruited, based on a predicted dropout rate of $10 \%$.

All data were expressed as median (IQR), or number of patients (\%). The normality of the data distribution was tested using the Kolmogorov-Smirnov test. We conducted Mann Whitney U-tests for continuous variables, and chisquare tests or Fisher's exact test for incidence variables. All statistical analyses were two-sided and performed with $\mathrm{R}$ software, version 3.6.1. A significance level of $\mathrm{P}<0.05$ was considered statistically significant.

\section{Results}

A total of 140 patients were recruited and assigned to either of two groups. Of these patients, 5 patients in each group were removed from the study. Finally, 130 patients completed all the assessments (Figure 1). There was no significant difference in patient characteristics between the groups, excepting height (Table 1).

There was a significant difference in the cough severity between the groups. The cough severity grading score is significantly lower in the magnesium group [median (IQR): 2 (0 to 3) in Group C vs. 0 (0 to 1 ) in Group M, $\mathrm{P}=0.003$ ]. For overall incidence of cough, there was no statistically significant difference between the two groups [42 patients (64.6\%) in Group C vs. 31 patients (47.7\%) in Group M, $\mathrm{P}=0.077]$. However, in the subgroup analysis, the incidence of severe cough (grade 3) was higher in the control group than in the magnesium group [17 patients $(26.2 \%)$ in Group C vs. 5 patients (7.7\%) in Group $\mathrm{M}, \mathrm{P}=0.010$, Table 2].

There were no differences in recovery profiles, except 


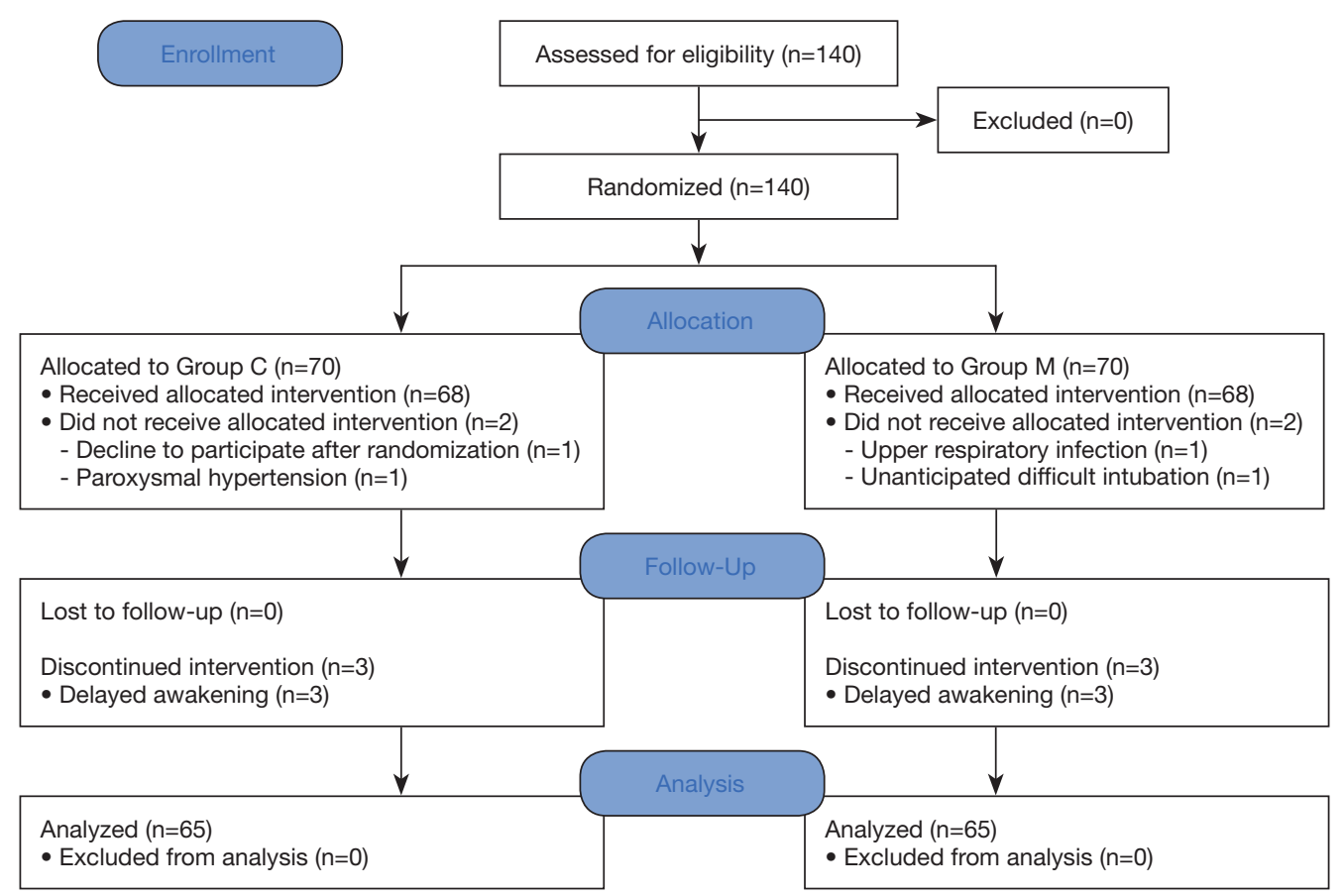

Figure 1 The CONSORT flow diagram.

Table 1 Characteristics and operative data of the patients

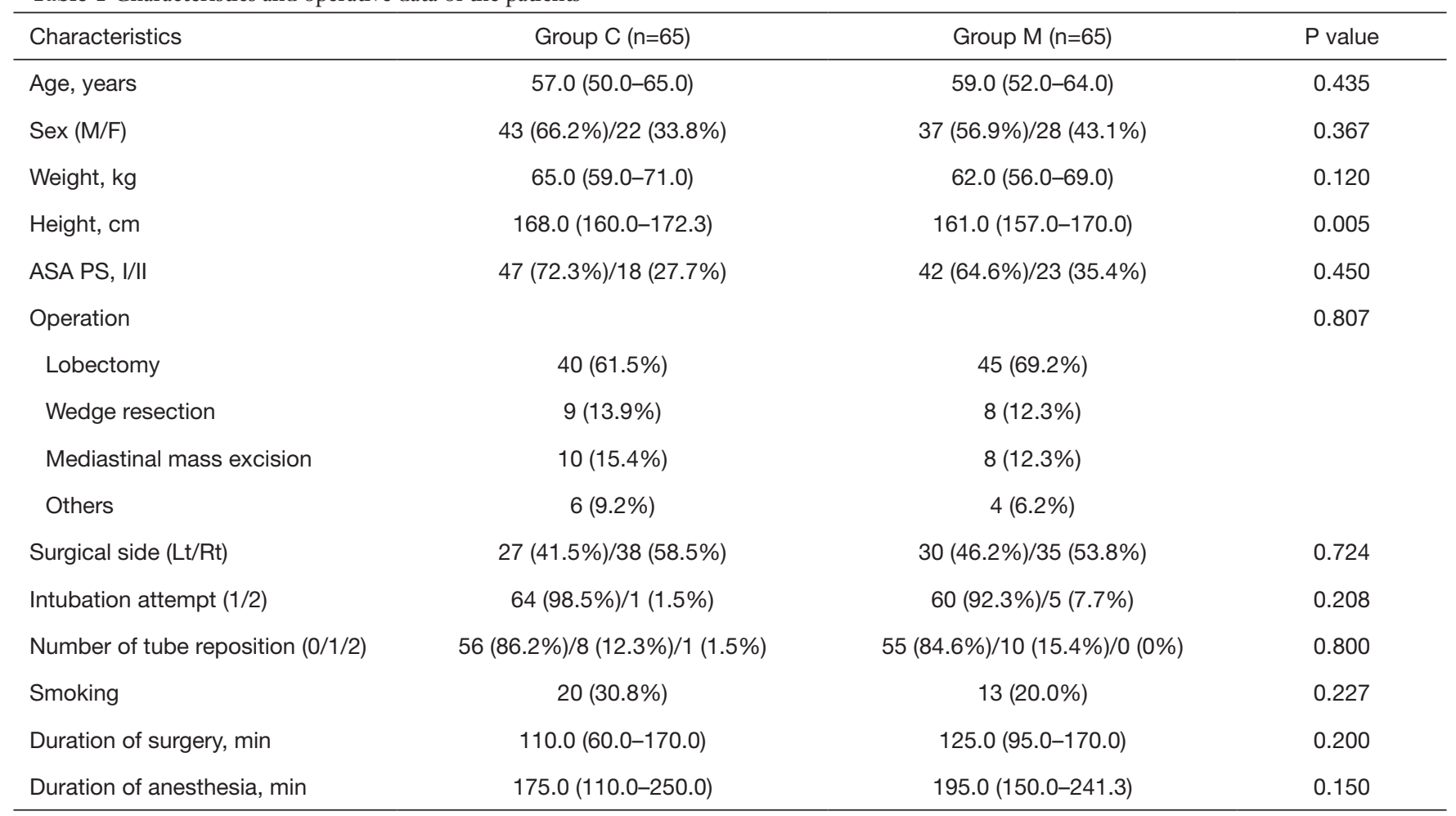

Values are presented as median (IQR) or number of patients (\%). Group C, control group; Group M, magnesium group; ASA PS, American Society of Anesthesiologists physical status. 
Table 2 The severity and incidence of emergence cough

\begin{tabular}{lccc}
\hline & Group C (n=65) & Group M (n=65) & $P$ value \\
\hline Cough severity grading score & $2(0$ to 3) & $0(0$ to 1$)$ & 0.003 \\
Overall incidence of cough & $42(64.6 \%)$ & $31(47.7 \%)$ & 0.077 \\
Subjects with severe cough (grade 3) & $17(26.2 \%)$ & $5(7.7 \%)$ & 0.010 \\
\hline
\end{tabular}

Values are presented as median (IQR) or number of patients (\%). Cough severity grading score: 0 , no cough; 1 , single cough; 2 , cough persistence $<5 \mathrm{~s} ; 3$, cough persistence $\geq 5 \mathrm{~s}$ (bucking). Severe cough (grade 3): cough persistence $\geq 5 \mathrm{~s}$ (bucking). Group C, control group; Group M, magnesium group.

Table 3 Comparison of recovery profiles

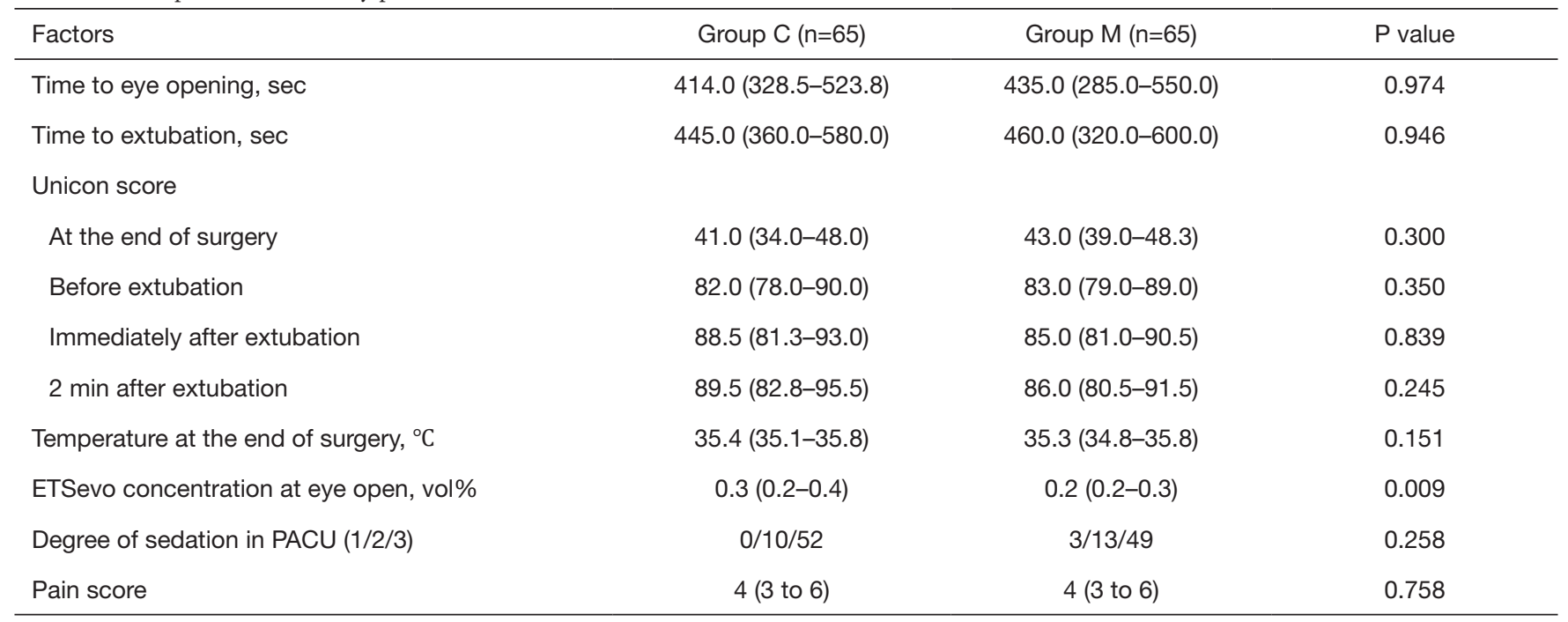

Values are presented as median (IQR) or number of patients. Degree of sedation, $0=$ no response to stimulus, $1=$ response to loud verbal stimulus or physical contact, 2 = response to general voice, 3 = clear consciousness. Group C, control group; Group M, magnesium group; ETSevo, end-tidal sevoflurane; PACU, post anesthesia care unit.

for ETSevo concentration at eye opening. This was significantly lower in the magnesium group than in control group (Table 3).

Concerning hemodynamic parameters, although heart rate was significantly lower in the magnesium group than in the control group during the emergence, no clinically significant hypotension or bradycardia was observed in either group (Table 4).

As one would expect, the plasma-ionized magnesium levels measured at the completion of surgery were higher in the magnesium infusion group as compared to the control group [median (IQR): 0.53 (0.47 to 0.57) in Group C vs. 0.81 (0.74 to 0.87 ) in Group $M, P<0.001$, Table 5].

No patients suffered any respiratory complications during the investigation.

\section{Discussion}

In this study, we evaluated the antitussive effects of intravenous magnesium during emergence after general anesthesia using DLT. To our knowledge, it is the first study that evaluates the effect of magnesium to prevent emergence cough. Our results showed that magnesium attenuated the severity of cough after OLV anesthesia using DLT. Although the infusion of magnesium didn't reduce the overall cough incidence, it reduced the incidence of severe cough, that is clinically important.

Magnesium has been used as an adjunct to general anesthesia. Various studies have demonstrated that the administration of intravenous magnesium has a beneficial effect of decreasing postoperative pain and reducing analgesic requirements (21-23). Although the mechanism 
Table 4 Comparison of hemodynamic profiles during anesthetic emergence

\begin{tabular}{|c|c|c|c|}
\hline & Group C (n=65) & Group M (n=65) & $\mathrm{P}$ value \\
\hline At the end of surgery & $81.0(75.0-91.0)$ & $82.0(76.0-93.0)$ & 0.631 \\
\hline Before extubation & $99.0(86.0-112.5)$ & $97.0(87.0-110.0)$ & 0.784 \\
\hline Immediately after extubation & $98.0(89.0-110.0)$ & $98.0(87.8-107.3)$ & 0.862 \\
\hline \multicolumn{4}{|l|}{$\mathrm{HR}, \mathrm{bpm}$} \\
\hline At the end of surgery & $73.0(64.0-82.0)$ & $65.0(58.0-71.0)$ & $<0.001$ \\
\hline Before extubation & $76.5(65.0-86.0)$ & $69.0(58.0-80.0)$ & 0.020 \\
\hline Immediately after extubation & $83.0(75.0-93.0)$ & $77.0(63.0-86.0)$ & 0.020 \\
\hline
\end{tabular}

Values are presented as median (IQR). Group C, control group; Group M, magnesium group; MAP, mean arterial pressure; HR, heart rate.

Table 5 Changes in plasma ionized magnesium levels

\begin{tabular}{llll}
\hline & Group C $(\mathrm{n}=65)$ & Group M $(\mathrm{n}=65)$ & $\mathrm{P}$ value \\
\hline Baseline, mmol/L & $0.53(0.49-0.58)$ & $0.56(0.52-0.60)$ & 0.174 \\
After infusion, $\mathrm{mmol} / \mathrm{L}$ & $0.53(0.47-0.57)$ & $0.81(0.74-0.87)$ & $<0.001$ \\
\hline
\end{tabular}

Values are presented as median (IQR). The reference range for ionized magnesium is $0.44-0.59 \mathrm{mmol} / \mathrm{L}$. Group C, control group; Group M, magnesium group.

through which systemic magnesium produces antinociceptive effects is still unclear, it is presumed that magnesium inhibits calcium influx, by acting as a calcium channel blocker (CCB) $(15,24)$ and that it is an antagonist of N-methyl-d-aspartate glutamate (NMDA) receptors $(11,22)$.

To date, two randomized controlled trials have evaluated the antitussive effect of magnesium $(17,18)$. These studies investigated the inhibitory effects of magnesium on opioid induced cough during anesthetic induction and demonstrated that magnesium could reduce the incidence and severity of cough caused by opioid. In contrast to these studies, intravenous infusion of magnesium in the present study didn't reduce the incidence of cough, but only alleviated the severity of emergence cough after general anesthesia using DLT. We speculate that these findings may be due to differences in the mechanisms of cough and the intensity of airway irritation. This theory is evidenced by previous studies that have reported the incidence of opioidinduced cough to range from $26 \%$ to $65 \%$ (25) whereas the incidence of emergence cough after a SLT or a DLT insertion tends to be somewhat higher, ranging from $72.6 \%$ to $90 \%(6,26-28)$.

There are several plausible hypotheses to explain why magnesium infusion could alleviate the severity of emergence cough. First, this result may be due to the bronchodilating effect of magnesium. It is well known that magnesium-induced bronchodilation occurs through several mechanisms: (I) inhibition of cholinergic NM transmission, (II) attenuation of calcium-induced muscle contractions, (III) anti-inflammatory activity, (IV) potentiation of agonists acting on adenylyl cyclase, prostaglandin-mediated vascular smooth muscle relaxation, and (V) the blockade of NMDA receptors in the larynx, lung, and airways $(15,17,18)$. Second, magnesium reduces muscle fiber excitability and the amplitude of endplate potential, by acting as a CCB at presynaptic nerve endings and decreasing acetylcholine release at the motor endplate $(17,18)$.

We should consider the other potential effects and actions of magnesium when using magnesium in perioperative management. There is substantial evidence that magnesium potentiates the effect of NM blocking agents $(17,18,29)$ 
and that it possesses sedative properties (30). These effects may result in delayed recovery from anesthesia (31). In addition, magnesium can cause cardiovascular side effects, including hypotension and bradycardia, and serious cardiac morbidity $(32,33)$. These side effects of magnesium are dose related (33). The magnesium dose administered in the present study-infusion of $15 \mathrm{mg} / \mathrm{kg} /$ hour after a single bolus of $30 \mathrm{mg} / \mathrm{kg}$ - are commonly used in the magnesium studies and have proven to be clinically safe (12). In our study, the plasma magnesium concentration after magnesium infusion was high enough compared with other studies $(22,23,34)$, given that it was in an ionized form (35). Also, consistent with previous literature, subjects in our study did not show any delay in recovery or adverse hemodynamic effects after magnesium infusion. Although heart rate was significantly lower in the magnesium group during emergence, no clinically significant hypotension or bradycardia was observed.

Our study had a few limitations that need to be addressed. First, because no studies have been conducted on the effect of magnesium in preventing emergence cough, when selecting the magnesium dose in the present study, we used the magnesium regimen that has been used in previous studies for analgesia in surgical patients (12). Further studies need to be done to reveal the exact magnesium dose in preventing the emergence cough. Second, we did not record the ETSevo concentration during the surgery. Because of the sedative effect of magnesium, the intraoperative ETSevo concentration was probably lower in the magnesium infusion group. This may have resulted in differences in ETSevo concentrations between the two groups at emergence in our study. Third, because all patients in our study were receiving remifentanil with magnesium at the time of anesthesia recovery, it is difficult to draw conclusions regarding the inhibitory effects of magnesium on emergence cough when magnesium is administered alone. Thus, we cannot rule out the effects of interactions, such as the additive or synergistic effects of magnesium and remifentanil. Fourth, muscle relaxation was not monitored using a NM monitor during the study, despite magnesium having been shown to potentiate non-depolarising NM blocking agents. Nevertheless, no clinical prolongation of recovery time was observed in the magnesium infusion group. Fifth, a $\mathrm{P}$ value of 0.077 in the overall incidence of coughing clearly points to an underpowered study. Posthoc power analysis revealed 0.50. Claiming that there is absolutely no difference between the groups is a type-II error and wrong conclusion.

\section{Conclusions}

Intravenous infusion of magnesium did attenuate the severity of emergence cough but did not reduce the incidence of emergence cough after OLV anesthesia using DLT. In addition, the administered doses of intravenous magnesium infusion did not affect the patient's recovery profile or cause any adverse hemodynamic effects during emergence.

\section{Acknowledgments}

Authors would like to thank Editage (www.editage.co.kr) for English language editing.

Funding: None.

\section{Footnote}

Reporting Checklist: The authors have completed the CONSORT reporting checklist. Available at http://dx.doi. org/10.21037/jtd-20-1977

Data Sharing Statement: Available at http://dx.doi. org/10.21037/jtd-20-1977

Peer Review File: Available at http://dx.doi.org/10.21037/jtd20-1977

Conflicts of Interest: All authors have completed the ICMJE uniform disclosure form (available at http://dx.doi. org/10.21037/jtd-20-1977). The authors have no conflicts of interest to declare.

Ethical Statement: The authors are accountable for all aspects of the work in ensuring that questions related to the accuracy or integrity of any part of the work are appropriately investigated and resolved. The trial was conducted in accordance with the Declaration of Helsinki (as revised in 2013) and the Harmonized Tripartite Guideline for Good Clinical Practice from the International Conference on Harmonization. The study was approved by the Institutional Review Board (Ref: AJIRB-MEDOBS-17-184) and was registered in a public trial registry (Clinical Research Information Service, CRIS) under the identification number KCT0002445. All patients enrolled completed the informed consent form.

Open Access Statement: This is an Open Access article 
distributed in accordance with the Creative Commons Attribution-NonCommercial-NoDerivs 4.0 International License (CC BY-NC-ND 4.0), which permits the noncommercial replication and distribution of the article with the strict proviso that no changes or edits are made and the original work is properly cited (including links to both the formal publication through the relevant DOI and the license). See: https://creativecommons.org/licenses/by-nc-nd/4.0/.

\section{References}

1. Clayton-Smith A, Bennett K, Alston RP, et al. A comparison of the efficacy and adverse effects of doublelumen endobronchial tubes and bronchial blockers in thoracic surgery: a systematic review and meta-analysis of randomized controlled trials. J Cardiothorac Vasc Anesth 2015;29:955-66.

2. Nishino T, Kochi T, Ishii M. Differences in respiratory reflex responses from the larynx, trachea, and bronchi in anesthetized female subjects. Anesthesiology 1996;84:70-4.

3. Nishino T. Physiological and pathophysiological implications of upper airway reflexes in humans. Jpn J Physiol 2000;50:3-14.

4. Sant'Ambrogio G. Afferent pathways for the cough reflex. Bull Eur Physiopathol Respir 1987;23 Suppl 10:19s-23s.

5. Tatar M, Sant'Ambrogio G, Sant'Ambrogio FB. Laryngeal and tracheobronchial cough in anesthetized dogs. J Appl Physiol (1985) 1994;76:2672-9.

6. Jun NH, Lee JW, Song JW, et al. Optimal effect-site concentration of remifentanil for preventing cough during emergence from sevoflurane-remifentanil anaesthesia. Anaesthesia 2010;65:930-5.

7. Guler G, Akin A, Tosun Z, et al. Single-dose dexmedetomidine attenuates airway and circulatory reflexes during extubation. Acta Anaesthesiol Scand 2005;49:1088-91.

8. Sumathi PA, Shenoy T, Ambareesha M, et al. Controlled comparison between betamethasone gel and lidocaine jelly applied over tracheal tube to reduce postoperative sore throat, cough, and hoarseness of voice. Br J Anaesth 2008;100:215-8.

9. Aouad MT, Al-Alami AA, Nasr VG, et al. The effect of low-dose remifentanil on responses to the endotracheal tube during emergence from general anesthesia. Anesth Analg 2009;108:1157-60.

10. Lee SY, Yoo JY, Kim JY, et al. Optimal effect-site concentration of remifentanil for preventing cough during removal of the double-lumen endotracheal tube from sevoflurane-remifentanil anesthesia: a prospective clinical trial. Medicine 2016;95:e3878.

11. Fawcett WJ, Haxby EJ, Male DA. Magnesium: physiology and pharmacology. Br J Anaesth 1999;83:302-20.

12. De Oliveira GS Jr, Castro-Alves LJ, Khan JH, et al. Perioperative systemic magnesium to minimize postoperative pain: a meta-analysis of randomized controlled trials. Anesthesiology 2013;119:178-90.

13. Spivey WH, Skobeloff EM, Levin RM. Effect of magnesium chloride on rabbit bronchial smooth muscle. Ann Emerg Med 1990;19:1107-12.

14. Aissaoui Y, Qamous Y, Serghini I, et al. Magnesium sulphate: an adjuvant to tracheal intubation without muscle relaxation - a randomised study. Eur J Anaesthesiol 2012;29:391-7.

15. Herroeder S, Schonherr ME, De Hert SG, et al. Magnesium - essentials for anesthesiologists. Anesthesiology 2011;114:971-93.

16. Shan $Z$, Rong $Y$, Yang $W$, et al. Intravenous and nebulized magnesium sulfate for treating acute asthma in adults and children: a systematic review and meta-analysis. Respir Med 2013;107:321-30.

17. An LJ, Gui B, Su Z, et al. Magnesium sulfate inhibits sufentanil-induced cough during anesthetic induction. Int J Clin Exp Med 2015;8:13864-8.

18. Liu HL, An LJ, Su Z, et al. Magnesium sulphate suppresses fentanyl-induced cough during general anesthesia induction: a double-blind, randomized, and placebocontrolled study. Int J Clin Exp Med 2015;8:11332-6.

19. Kim DH, Yoo JY, Kim JY, et al. Influence of electrocautery-induced electromagnetic interference on quantitative electroencephalographic monitoring of hypnosis during general anesthesia: comparison between the $\mathrm{ADMS}^{\circledast}$ and the BIS VISTA ${ }^{\mathrm{TM}}$. Korean J Anesthesiol 2018;71:368-73.

20. Jensen EW. New findings and trends for depth of anesthesia monitoring. Korean J Anesthesiol 2018;71:343-4.

21. Sousa AM, Rosado GM, Neto Jde S, et al. Magnesium sulfate improves postoperative analgesia in laparoscopic gynecologic surgeries: a double-blind randomized controlled trial. J Clin Anesth 2016;34:379-84.

22. Hwang JY, Na HS, Jeon YT, et al. Infusion of magnesium sulphate during spinal anaesthesia improves postoperative analgesia. Br J Anaesth 2010;104:89-93.

23. Shin HJ, Kim EY, Na HS, et al. Magnesium sulphate attenuates acute postoperative pain and increased pain intensity after surgical injury in staged bilateral total knee 
arthroplasty: a randomized, double-blinded, placebocontrolled trial. Br J Anaesth 2016;117:497-503.

24. Dubé L, Granry JC. The therapeutic use of magnesium in anesthesiology, intensive care and emergency medicine: a review. Can J Anaesth 2003;50:732-46.

25. Sun L, Guo R, Sun L. The impact of prophylactic intravenous lidocaine on opioidinduced cough: a metaanalysis of randomized controlled trials. J Anesth 2014;28:325-33.

26. Tanoubi I, Sun JN, Drolet P, et al. Replacing a doublelumen tube with a single-lumen tube or a laryngeal mask airway device to reduce coughing at emergence after thoracic surgery: a randomized controlled single-blind trial. Can J Anaesth 2015;62:988-95.

27. Ghodraty MR, Hasani V, Bagheri-Aghdam A, et al. Remifentanil infusion during emergence moderates hemodynamic and cough responses to the tracheal tube: a randomized controlled trial. J Clin Anesth 2016;33:514-20.

28. Fang P, Zong Z, Lu Y, et al. Effect of topical ropivacaine on the response to endotracheal tube during emergence from general anesthesia: a prospective randomized doubleblind controlled study. BMC Anesthesiol 2018;18:134.

29. Kussman B, Shorten G, Uppington J, et al. Administration of magnesium sulphate before rocuronium: effects on

Cite this article as: Hur M, Kim JY, Kim DH, Yoo JY, Shin HB, Park B, Kim M, Park E, Park SY. Antitussive effect of a magnesium infusion during anesthetic emergence in patients with double-lumen endotracheal tube: a randomized controlled trial. J Thorac Dis 2020;12(10):5691-5699. doi: 10.21037/jtd20-1977 speed of onset and duration of neuromuscular block. Br J Anaesth 1997;79:122-4.

30. Olgun B, Oguz G, Kaya M, et al. The effects of magnesium sulphate on desflurane requirement, early recovery and postoperative analgesia in laparascopic cholecystectomy. Magnes Res 2012;25:72-8.

31. Gupta K, Vohra V, Sood J. The role of magnesium as an adjuvant during general anaesthesia. Anaesthesia 2006;61:1058-63.

32. Vissers RJ, Purssell R. Iatrogenic magnesium overdose: two case reports. J Emerg Med 1996;14:187-91.

33. Seyhan TO, Tugrul M, Sungur MO, et al. Effects of three different dose regimens of magnesium on propofol requirements, haemodynamic variables and postoperative pain relief in gynaecological surgery. Br J Anaesth 2006;96:247-52.

34. Na HS, Shin HJ, Kang SB, et al. Effects of magnesium sulphate on coagulation after laparoscopic colorectal cancer surgery, measured by rotational thromboelastometry $\left(\right.$ ROTEM $\left.^{\circledR}\right)$. Anaesthesia 2014;69:1314-21.

35. Greenway DC, Hindmarsh JT, Wang J, et al. Reference interval for whole blood ionized magnesium in a healthy population and the stability of ionized magnesium under varied laboratory conditions. Clin Biochem 1996;29:515-20. 